\title{
VALORES ESTÉTICOS, ACERVOS IMAGÉTICOS E PROCEDIMENTOS ESTRUTURADOS: AMPLIANDO E DESCOLONIZANDO A REFLEXÁO FILOSÓFICA SOBRE A TECNOLOGIA
}

\author{
Cristiano Cordeiro Cruz ${ }^{1}$
}

\begin{abstract}
RESUMO. Desde os anos 1980, reconhecem-se como partes constitutivas da tecnologia e do seu desenvolvimento o conhecimento técnico-científico e os valores instrumentais e cognitivos que balizam tal conhecimento, bem como valores ético-políticos. No entanto, segue grandemente negligenciada ou desconhecida uma quarta categoria de elementos que incidem no projeto: acervos imagéticos, valores estéticos e procedimentos estruturados. A desconsideração desses elementos impóe limites ao desenvolvimento técnico possível. Neste artigo, serão apresentados essa quarta categoria de elementos, o impacto dela sobre a prática projetiva e as soluçóes sociotécnicas construídas, e uma forma de pluralizar seus conteúdos. Será exposto também um esboço de duas das abordagens mais exitosas para a democratização do desenvolvimento técnico. A partir disso, seráo discutidos: alguns limites e potencialidades da democratização da tecnologia; uma atualização de parte da compreensão simondoniana de desenvolvimento técnico; a necessidade teórica e prática de se descolonizar (ou seguir descolonizando) a filosofia da tecnologia.
\end{abstract}

Palavras-chave: Valores estéticos. Acervos imagéticos. Procedimentos estruturados. Democratização. Descolonização.

\section{INTRODUÇÃo}

Desde a década de 1980, estudos sociológicos, históricos e filosóficos vêm revelando a tecnologia, em sua forma material ou imaterial, como construção para a qual são insuficientes valores instrumentais (como eficiência, eficácia, robustez, durabilidade etc.) e cognitivos (como precisão, capacidade preditiva, coerência, consistência etc.). Com efeito, considerando-se apenas tais valores, seria impossível proceder-se à escolha da solução técnica final, dentre as múltiplas opçóes disponíveis ou passíveis de serem desenvolvidas para ela.

\footnotetext{
${ }^{1}$ Pós-doutorado no Instituto Tecnológico de Aeronáutica (ITA), São José dos Campos, SP - Brasil.

(D) https://orcid.org/0000-0003-2844-3439 E-mail: cristianoccruz@yahoo.com.br
}

https://doi.org/10.1590/0101-3173.2021.v44dossier.11.p207

\section{(i)}


Essa multiplicidade é chamada de subdeterminação da solução pelo problema e pelos dados iniciais. Ela só pode ser superada, e uma solução escolhida, por meio da intervenção, no desenvolvimento tecnológico, de valores éticopolíticos (como controle/dominação, empoderamento, lucro, bem comum, hierarquização etc.). É esse mesmo tipo de intervenção ou conformação que explicará, igualmente, muito do desenvolvimento e das modificaçóes por que um produto técnico passará, depois de criado (WINNER, 2017 [1986]; PINCH; BIJKER, 1989; FEENBERG, 2019a [2010]).

Porque incorpora valores ético-políticos em sua constituição e porque, uma vez que essa tecnologia é colocada em uso, tais valores são reforçados ou emulados socialmente, entende-se: 1) que sociedade e tecnologia se conformam mutuamente, constituindo partes inseparáveis de uma realidade sociotécnica una (DAGNINO et al., 2004, p. 22-23); 2) que a tecnologia legisla sobre o mundo da vida, sendo, por vezes, mais rigorosa e eficaz na conformação do nosso comportamento e do funcionamento da sociedade, do que as leis que o Legislativo cria (LATOUR, 1992).

O que a compreensão mais recente sobre a tecnologia nos revela, assim, é que o seu desenvolvimento não é regido por uma racionalidade instrumental (HORKHEIMER; ADORNO, 2002 [1944]) ou tecnológica (MARCUSE, 2002 [1964]) puras, nem é tocado de forma autônoma e autorreferenciada (ELLUL, 2008 [1954], 2012 [1977]). Tampouco, a tecnologia nos aprisionaria ontologicamente em uma dispensação singular do Ser, reduzindo-nos a uma existência inautêntica (HEIDEGGER, 1977 [1955], 1998 [1962]). Presidiria, ao contrário, ao seu desenvolvimento, uma racionalidade sociotécnica (FEENBERG, 2019b [2017]), de sorte que tal processo se constituiria, pela própria natureza da tecnologia, em uma agora, em um espaço público de luta em torno ao ideário ético-político que democraticamente pudéssemos querer como conformador da tecnologia e, nisso, da nossa vida em comum.

Não obstante, embora esse entendimento seja bastante defensável e conte, inclusive, com inúmeros exemplos empíricos a corroborá-lo, tal descrição do fenômeno sociotécnico ainda é imprecisa. Essa imprecisão, associada com um apartamento por vezes excessivo - e superável - entre a reflexão filosófica sobre a tecnologia e a manifestação empírica desta, traz limites, por um lado, para algumas reflexôes relativas à democratização do desenvolvimento tecnológico, relativos, aqui, às condiçóes para, e aos limites efetivos de, um tal processo. Por outro lado, essa situação demanda também que compreensóes filosóficas poderosas sobre a tecnologia, como as do 
pensador francês Gilbert Simondon, sejam matizadas, de modo que não sejam tomadas como fundamentos para reflexôes ou argumentos já superados.

Nesse sentido, naquilo que se segue, buscar-se-á apresentar não apenas práticas correntemente bem avançadas de democratização do desenvolvimento tecnológico - já bem conhecidas e documentadas - (parte 2), sobretudo em relação a trabalhos desenvolvidos em algumas engenharias, quanto a amplamente desconsiderada dimensão poiético-criativa do projeto técnico, na qual uma quarta categoria de elementos, os quais não são instrumentais, cognitivos ou ético-políticos, desempenha papel central (parte 3).

Com isso, ao lado de se prover uma caracterização empiricamente mais acurada de parte daquilo que constitui o fenômeno tecnológico, procurar-se-á apresentar ponderaçôes concernentes à democratização do desenvolvimento tecnológico e ao aparente "purismo axiológico" do desenvolvimento técnico autêntico de Simondon (parte 4). Por fim, nas consideraçôes finais, será apontado um possível caminho para lidarmos não somente com as questóes trabalhadas na parte 4, mas com o alargamento da reflexão filosófica da tecnologia em geral, o da descolonização.

\section{Projetos emancipadores}

Democratizar o desenvolvimento tecnológico significa, em uma primeira aproximação, incorporar ou considerar, no/ao projeto técnico, ${ }^{2}$ os valores ético-políticos de futuros usuários, consumidores e demais atores direta ou indiretamente afetados pela solução que se irá construir. Historicamente, tal coisa tem lugar pela primeira vez, de forma mais sistemática, consciente e consistente, com as iniciativas de informatização dos espaços de trabalho na Escandinávia fortemente sindicalizada da década de 1970 (ROBERTSON; SIMONSEN, 2013). Desde esse período, a assim chamada prática de projetos participativos diversificou-se e se consolidou grandemente, contando com metodologias e procedimentos bem desenvolvidos, com aplicação nos mais variados espaços sociais (para além do laboral) e em diversas áreas técnicas, e com usos tanto socialmente emancipadores quanto mais mercadologicamente

\footnotetext{
2 Manteremos "projeto", em lugar de "design", por conta de ser essa a preferência majoritária para a tradução do termo nos manuais de engenharia (Pahl et al. (2005); Dym e Little (2010)). Como se está procurando refletir a tecnologia aqui também em diálogo com a engenharia, não parece razoável adotar uma terminologia que, além de anglicista, não encontra referente efetivo na prática que almeja analisar.
} 
orientados (VAN DER VELDEN; MÖRTBERG, 2015; BANNON; EHN, 2013; ROBERTSON; SIMONSEN, 2013; VAN DE POEL, 2015).

O maior potencial democratizante, de todo modo, é alcançado pelos projetos participativos de vertente emancipadora. ${ }^{3}$ Isso se deve ao fato de, apenas neles, futuros usuários e demais atores concernidos - os coprojetistas - poderem tomar parte em todas as etapas do projeto ${ }^{4}$ (excetuando-se, via de regra, a etapa de implementação da solução conceitual escolhida) (IVERSEN et al., 2012; VAN DER VELDEN; MÖRTBERG, 2015). Tal coisa assegura aos coprojetistas espaço não só para terem suas demandas e seus valores apreendidos pelos projetistas (i.e., equipe técnica) e incorporados à solução técnica que se irá construir, como também para antever eventuais efeitos colaterais não desejáveis dela e, também a partir disso, alterar o projeto e a ordem sociotécnica que tal soluçáo em projeto tenderá a construir ou reforçar.

$\mathrm{Na}$ América Latina, abordagens técnicas emancipadoras ganham força sobretudo a partir da década de 1990, com o surgimento da tecnologia social (TS). Uma genealogia da TS, porém, não encontrará as suas raízes nos projetos participativos escandinavos, mas no encontro do movimento da tecnologia apropriada com práticas e ideários libertadores do continente (THOMAS, 2009). É nesse sentido que a TS abandonará a perspectiva acrítica, de mero barateamento de tecnologias consolidadas nos países centrais e conformadora de um ordenamento sociotécnico muito afinado com a ordem capitalista hegemônica da tecnologia apropriada, substituindo-a por projetos tecnológicos que buscam incorporar os saberes dos grupos locais e ser mediação para a emancipação desses grupos (THOMAS, 2009). Dessa maneira, tais soluçóes se pretendem também espaço para se sonharem outros mundos possíveis e, a partir disso, coconstruí-los.

Uma das formas como os projetos de TS são atualmente construídos, no Brasil, é a engenharia popular (EP). Ela começa a se constituir a partir de

\footnotetext{
${ }^{3}$ A rigor, a democratização defendida por Feenberg (1999) é um processo que pressupóe e que implica, da parte de quem luta por ela, aumento de conscientização, empoderamento ou emancipação, na maneira como esses termos são entendidos por Paulo Freire (1987 [1970]; FREIRE; SHOR, 1986). Freire (1983 [1969]), aliás, defende que a assistência técnica seja oportunidade de se praticar educação popular (ainda que sua compreensáo de tecnologia pareça aproximar-se, como náo poderia ser muito diferente nessa época, de uma perspectiva instrumental).

${ }^{4}$ Como se apresentará com mais detalhes na terceira parte deste artigo, o projeto técnico é constituído por várias etapas que costumam ser seguidas de forma iterativa e não linear: análise e formulação do problema; projeto conceitual; escolha da solução conceitual que será implementada; implementação dessa solução; projeto detalhado para se construir essa solução.
} 
meados da década de 2000, caracterizando-se por diferentes metodologias que lançam mão, via de regra, de pesquisa-ação, educação popular e ferramentais outros, como a ergonomia da atividade (CRUZ, 2020). A EP é, além disso, fortemente tributária dos ideais da economia solidária, sendo majoritariamente praticada a partir da extensão universitária (FRAGA et al. 2020).

Tomados comparativamente, os projetos participativos emancipadores e a EP partilham de um mesmo ideário comum, o qual é o do empoderamento dos coprojetistas e o da construção de outra ordem sociotécnica possível, que seja menos opressora, menos injusta e mais sustentável ecologicamente. Os referenciais teóricos e as metodologias desenvolvidas em cada caso, por outro lado, podem variar em maior ou menor grau. Além disso, por conta dos grupos com os quais tende a trabalhar mais frequentemente e à filiação à tradição crítica latino-americana, a EP dá especial atenção aos saberes desses grupos e às suas cosmovisóes. Ela busca, com isso, escutar e trabalhar tais elementos, por meio da educação popular, incorporando-os às soluçôes sociotécnicas construídas e ao seu próprio modo de atuar. Nesse sentido, a EP se pretende também uma prática de projeto tecnológico que é coconstruída, em parte ao menos, com grupos populares com os quais ela atua.

\section{ACERVOS IMAGÉTICOS, VALORES ESTÉTICOS E PROCEDIMENTOS ESTRUTURADOS}

Se a incidência de valores ético-políticos nos projetos técnicos é já bem conhecida, assim como são bem documentadas as abordagens democratizantes desse processo, pouco ou nada existe de forma mais sistematizada sobre a incidência de um quarto tipo de elementos no projeto, os quais não são instrumentais, cognitivos ou ético-políticos: valores estéticos, acervos imagéticos e procedimentos estruturados. E, por essa razão, metodologias para a pluralização deles no projeto técnico são praticamente inexistentes ou não têm esse potencial de pluralização identificado ou valorizado como tal.

A incidência dessa quarta categoria de elementos náo costuma se dar nas mesmas etapas em que os valores ético-políticos impactam e conformam o projeto. Assumindo-se, como o sustenta Van de Poel (2009, p. 985), que os projetos técnicos tenham cinco estágios principais (que são percorridos de maneira usualmente iterativa e não linear, afetando-se e interpenetrando-se reciprocamente), tais estágios ou etapas podem ser assim definidos: ${ }^{5}$

${ }^{5}$ A rigor, segundo o modo que se busca ou se assume como ideal na engenharia, atualmente, ao
longo dessas etapas, devem ser consideradas, adicionalmente, questôes relativas também à fabricação 
1. Análise e formulaçáo do problema, incluindo a formulaçáo dos requisitos do projeto e o plano do projeto e do desenvolvimento do produto, sistema ou serviço;

2. Projeto conceitual, englobando a criação de soluçóes conceituais alternativas para o problema do projeto, bem como uma possível reformulação do problema;

3. Escolha, dentro do conjunto das soluçôes conceituais desenvolvidas, daquela que será implementada;

4. Desenvolvimento da solução escolhida em termos estruturais, materiais e/ou procedimentais;

5. Projeto detalhado, isto é, redação de todas as informaçóes e orientaçóes necessárias para que a soluçáo possa ser produzida ou implementada comercialmente (em massa).

Assim, não é difícil perceber que os valores ético-políticos têm particular relevância nos estágios um e três (VAN DE POEL, 2009, p. 986). De sua parte, como se depreenderá do que se desenvolverá nas próximas páginas, valores estéticos, procedimentos estruturados e acervos imagéticos atuam, sobretudo, ainda que não exclusivamente, nas etapas dois e quatro.

A conjugação dos valores estéticos com o acervo imagético (válido, como se verá, principalmente para soluçôes técnicas materiais) caracteriza uma dimensão inevitável da prática projetiva, dimensão que, nos termos de Eugene Ferguson (1992), constitui a arte da engenharia. A conjugação desses dois elementos com procedimentos estruturados leva à constituiçáo de estilos de projeto, os quais, em uma mesma área técnica, poderão se prestar melhor, cada qual, a classes específicas de soluçóes, funcionalidades e/ou valores éticopolíticos.

Com isso, ao náo se considerar e tratar de forma apropriada essa quarta categoria de elementos que incidem no projeto, não somente possíveis novas funcionalidades ou aprimoramentos em funcionalidades existentes podem ficar bloqueados, como também implementaçóes eventualmente interessantes

da solução construída (quando se trata de algo a ser produzido em massa), à manutençấo desta e, no caso de objetos materiais, à destinação adequada tanto dos rejeitos do processo projetivo/produtivo quanto do artefato produzido, quando do descarte deste pelo usuário/consumidor (PAHL et al., 2005; DYM; LITTLE, 2010). 
para articulaçóes de valores ético-políticos que se estejam procurando avançar sociotecnicamente podem permanecer não concebíveis ou implementáveis.

Nas próximas páginas, será desenvolvida a reflexão sobre o impacto desses elementos no projeto técnico do modo mais completo possível para o espaço que temos aqui disponível. Seguiremos, para tanto, em diálogo com Eugene Ferguson e Walter Vincenti, complementado por contribuiçôes mais pontuais de outros autores. $\mathrm{Na}$ sequência, será apresentado um caminho metodológico possível, para se alcançar essa pluralização de estilos aqui defendida.

\subsection{InSTRUMENTALIDAdES DO PROJECTO E PLURALIZAÇÁO}

Acervos imagéticos, valores estéticos e procedimentos estruturados constituem parte do conteúdo de três tipos de conhecimento que Vincenti (1990) identifica como demandados nos projetos de engenharia, os quais ele agrupa em uma categoria a que chama de instrumentalidades do projeto. Tratase de modos de pensar, habilidades avaliativas e procedimentos estruturados.

Com vistas a construir um projeto, a equipe técnica sempre lança mão de procedimentos estruturados bem conhecidos. É o caso da divisão de um projeto geral (p.e., avião) em suas subpartes (p.e., estrutura, motor e hélice) e destas em suas componentes etc. (VINCENTI, 1990, p. 220). Também é o que acontece quando, diante de funcionalidade(s) e requisitos definidos (estágio um), procede-se aos possíveis projetos conceituais da solução perseguida (estágio dois) e, daí, para a construção material e/ou procedimental dela (estágio quatro) e o detalhamento desse processo de construção (estágio cinco).

Nesse processo, pode-se lançar mão de procedimentos que conduzem: 1) do abstrato (funcionalidade(s) e requisitos) para o detalhe (processo de construção detalhado), seguindo os estágios dois, quatro e cinco descendentemente; 2) do detalhe (solução/óes já existente(s) no mercado) para o detalhe (adaptação dessas soluçôes para se obter aquilo que se está perseguindo), saltando-se do estágio um para o quatro e, daí, o cinco; ou 3) do detalhe (solução/óes existentes no mercado) para o abstrato (possíveis projetos conceituais inspirados nessas soluçôes) e deste para o detalhe (processo de construção detalhado da solução obtida), ou seja, tomam-se soluçóes já existentes como inspiração para o projeto conceitual (estágio dois), seguindo- 
se descendentemente do estágio quatro para o cinco, a partir daí (SPITAS, 2011a, p. 430-431, 2011b, p. 450-453).

Entre os procedimentos estruturados e as habilidades avaliativas, bem menos estruturadas, isto é, menos explícitas ou formalizadas (ou mais tácitas), encontram-se os modos de pensar. Eles se referem, por exemplo, aos modos comuns, partilhados pelos engenheiros, de apreender a operação do dispositivo e imaginar o efeito que alteraçóes em seu projeto poderiam provocar. Outro caso de modo de pensar comum nos projetos de engenharia é, por analogia, partir-se de um tipo particular de pensamento para encontrar conceitos que se adequem à situação em análise (como, por exemplo, tomar os sistemas hidráulicos como análogos aos elétricos que se quer conhecer melhor). Um terceiro modo de pensar é o visual, no sentido daquilo que Ferguson (1992) afirma que todo projetista extraordinário é invariavelmente um extraordinário pensador visual (VINCENTI, 1990, p. 220-2). É este último que nos interessa, de maneira particular aqui.

Por fim, dentre as instrumentalidades do projeto, temos as habilidades avaliativas, que estão associadas, por exemplo, à percepção e busca por uma solução que seja, de acordo com os valores assumidos, bela, elegante, adequada e/ou etc. "Tais habilidades, do mesmo modo que no pensamento visual, requerem inspiração, imaginação e intuição, assim como um senso de elegância e de estética no projeto técnico." (VINCENTI, 1990, p. 222). ${ }^{6}$ Por isso, elas são mais tácitas e menos "objetivamente aprendíveis", demandando, para serem internalizadas, vivência, imersão e abertura da parte dos engenheiros (VINCENTI, 1990, p. 222).

PENSAMENTO IMAGÉTICO. No que concerne à importância das imagens e do pensamento imagético no projeto de soluçóes técnicas materiais (estágios dois e quatro do projeto), já existe uma ampla bibliografia a fundamentar e ilustrar esse entendimento. De uma forma ou de outra, tendese a convergir, nesse domínio de pesquisa, para a conclusão de que as imagens (mentais e desenhos) são cruciais para o desenvolvimento de novos artefatos e de parte do conhecimento associado a tais projetos (AMMON, 2017). Com efeito, elas operam tanto como disparador da criatividade e como léxico por meio do qual os projetistas conseguem imaginar, articular e comunicar suas ideias (FERGUSON, 1992; AMMON; CAPDEVILA-WERNING, 2017; GOLDSCHMIDT, 2017) quanto como instrumentos para a reflexão e para

${ }^{6}$ Aqui e em todas as demais citações apresentadas ao longo do texto, as traduçôes são de nossa autoria. 
descobertas relativas ao projeto (AMMON, 2017; GOLDSCHMIDT, 2017; SUWA et al., 2000; CURRIE, 2003).

Nesse sentido, as imagens constituem um acervo sem o qual o projeto não tem como acontecer, e um acervo que, quanto mais extenso, maior plasticidade e criatividade parece facultar ao projetista (FERGUSON, 1992, p. 115-130). De igual modo, quanto mais plural é a estimulação imagética externa a que o projetista se encontra submetido, tanto maior tende a ser a sua possibilidade de conceber uma soluçấo criativa. Tais imagens, com efeito, possibilitam a uma mente treinada obter inspiração para se guiar, no projeto com o qual está envolvida, em meio às escolhas aleatórias que esse processo projetivo (i.e., estágios dois e quatro) traz inevitavelmente consigo (GOLDSCHMIDT, 2017).

HABILIDADES AVALIATIVAS. Ao contrário do que somos levados a acreditar por uma certa compreensão sobre os estágios dois e quatro do projeto técnico, há, mesmo neles, mais julgamento - calcado em valores que não são nem instrumentais nem cognitivos - do que verdades/ soluçôes autoevidentes ou a que se pode chegar, através apenas do conhecimento técnico-científico disponível e/ou dos valores instrumentais e cognitivos que os balizam (FERGUSON, 1992, p. 22). Isso pode ser dito ao menos com respeito ao projeto de uma solução inédita (FERGUSON, 1992, p. 173, 194).

As habilidades avaliativas de Vincenti lidam precisamente com esse tipo de julgamento. Por sua natureza, os valores que as balizam não são cognitivos, instrumentais ou ético-políticos. Schummer e seus coatores (2009) chamamnos de valores estéticos, termo que manteremos. Exemplos desse tipo de valor, ao modo como ele se materializa em práticas projetivas da arquitetura, síntese química e engenharia de software, mas que parecem igualmente aplicáveis às outras áreas técnicas, vão desde a simetria e a simplicidade (ou o rebuscamento) até padróes ou ideais de beleza e harmonia específicos (SCHUMMER et al., 2009, p. 1032, 1045).

A questão particularmente interessante, com respeito aos valores estéticos a balizarem a prática projetiva, é que, ao mesmo tempo que eles podem ser úteis ou profícuos na concepção e construção de determinados arranjos e funcionalidades, eles podem igualmente interditar outros arranjos ou funcionalidades que poderiam ser acessíveis, caso outros valores estéticos estivessem sendo considerados no projeto (SCHUMMER et al., 2009, p. 1044-54). 
Disso decorre que, assim como no caso do acervo imagético, a pluralização, em uma mesma área técnica, de valores estéticos a conformarem os estágios dois e quatro do projeto, pode implicar a possibilidade de concepção e viabilização de soluções até então inconcebíveis ou inviáveis. E soluções que podem ser de particular importância ético-política (ou econômica).

PROCEDIMENTOS ESTRUTURADOS. Ainda que, como se disse antes, procedimentos estruturados sejam a mais estruturada das três instrumentalidades, isto é, a mais explícita e formalizada (ou a menos tácita), procedimentos distintos para uma mesma atividade ou resultado pretendido podem conduzir a soluções, em alguma medida não desprezível, diferentes. No exemplo apresentado anteriormente, dos tipos de procedimentos possíveis para se caminhar do estágio um (funcionalidade(s) e requisitos) ao cinco (detalhamento do processo de produção da solução final) do projeto, Spitas (2011a; 2011b) não somente inventariou, de forma não exaustiva, seis procedimentos diferentes para esses três modos de proceder a tal tradução, como identificou no modo "do detalhe para o detalhe" uma impossibilidade quase total de produzir uma solução em alguma medida inédita, ao passo que os outros dois modos tenderiam a favorecê-la, em alguma medida.

Diversidade equivalente de procedimentos, mas com impacto possível não apenas no grau de ineditismo da solução final construída, como também na estruturação da atividade projetiva, é atestada no domínio da engenharia de software, no âmbito das comunidades de projetistas-usuários que se constroem em torno a programas, sistemas e aplicaçóes de código aberto (RIEDER; SCHÄFER, 2008). Dentre outras coisas, tais estruturaçôes (ou procedimentos estruturados) evidenciam que "extensōes às metodologias clássicas, rotas alternativas, abordagens colaborativas e formas auto-organizadas de fluxo de trabalho são tanto possíveis quanto efetivas." (RIEDER; SCHÄFER, 2008, p. 170).

Ao lado disso, a pluralização de procedimentos estruturados tem papel também relevante na constituição de estilos de projeto diferentes em uma área técnica (SCHUMMER et al., 2009, p. 1051). Com efeito, é apenas a adequada construção ou apropriação de procedimentos estruturados e, quando o caso, também de acervos imagéticos, em resposta ao, ou em sintonia com o valor (ou valores) estético(s) assumido(s), que pode garantir a formação de um estilo efetivamente profícuo ou interessante. ${ }^{?}$

\footnotetext{
7 Que, na constituiçấo de um novo estilo de projeto, os valores estéticos desempenhem um papel estruturante, isso é o que é ilustrado por estudos empíricos como os de Ball (2005) e Schummer et al. (2009).
} 
Para ilustrar isso, tome-se o exemplo, analisado por Schummer e seus coautores (2009), da constituição do estilo de síntese química que acabou por possibilitar a nanotecnologia. Ele emerge no contexto do desenvolvimento de técnicas de representação visual da estrutura molecular das substâncias, assim como de artefatos e procedimentos que possibilitaram enxergar tais estruturas. A partir disso, surgirá, em vários pesquisadores, o fascínio por estruturas moleculares cujas representações eram iguais a (ou muito parecidas com) objetos macroscópicos. Perseguida inicialmente por si mesma, a construção dessas estruturas obrigará aqueles que se dedicavam a ela a desenvolverem ou aprimorarem instrumentais e procedimentos que possibilitassem tal construção. Será somente a partir desse esforço - e do êxito nele -, então, que emergirá ou se tornará possível/viável, a nanotecnologia (SCHUMMER et al., 2009, p. 1048-1049).

Nesse sentido, a constituição de novos procedimentos estruturados, seja para se obterem resultados em alguma medida similares aos que já são alcançáveis por outros meios (como nos procedimentos de tradução de funcionalidade(s) e requisitos em detalhamento do processo de produção da solução final), seja para se conseguir realizar o que ainda náo se consegue (como nos procedimentos para se conseguir copiar o mundo macroscópico em dimensão molecular), pode trazer impacto não desprezível com respeito àquilo que passamos a ser capazes de projetar e/ou construir a partir daí.

\subsection{INSERÇÁO, DiÁLOGO DE SABERES E CUIDADO}

Até onde se conseguiu ir na revisão bibliográfica que fundamenta esta pesquisa, náo existe sequer um procedimento sistematizado e que tenha como objetivo explícito a pluralização do conteúdo das instrumentalidades do projeto. Isso parece ser o caso, ao menos em parte, porque o caráter em alguma medida contingente de tais conteúdos (i.e., acervos imagéticos, valores estéticos e procedimentos estruturados) e o impacto da diversificação deles na prática projetiva seguem grandemente negligenciados ou desconhecidos.

Há, não obstante, modos de proceder a projetos emancipadores que parecem bastante promissores também para tal fim. Nesta segunda seção, apresentaremos um deles, que foi codesenvolvido e aplicado pela etnógrafa colombiana Tania Pérez-Bustos, em uma iniciativa de produção tecnológica junto a um grupo de bordadeiras de Cartago, Colômbia. Trata-se aqui da construçáo de um projeto participativo e que teve como resultado algo que 
pode ser entendido como uma tecnologia social. São igualmente promissores quanto à diversificação de acervos imagéticos, valores estéticos e procedimentos estruturados certas abordagens de engenharia popular e de projetos em arquitetura (Techné).

A equipe de Tania era composta por Laura Cortés-Rico, a engenheira que implementará o artefato, além de outros dois engenheiros e uma segunda etnógrafa (RIVERA et al., 2016). O trabalho que essa equipe se propôs desenvolver tinha explicitamente como um de seus pressupostos o reconhecimento e a valorização dos saberes das bordadeiras. De sorte a se assegurar tal coisa, assim como a escuta em profundidade das reais demandas e dos valores e ideais dessas mulheres, o trabalho das etnógrafas foi fundamental. Ele possibilitou, ao fim e ao cabo, que Laura incorporasse à confecção do hardware (i.e., elementos tangíveis condutores que permitiam a construção de padrôes do bordado na tela touch de um tablet) e do software (i.e., reconhecimento dos padrôes do bordado pressionados sobre a tela) saberes que as bordadeiras detinham relativamente à produção do calado (o tipo de bordado que o grupo produzia), assim como saberes a que ela teve acesso no convívio com essas mulheres e nas lições de bordado que tomara com elas (RIVERA et al., 2016; PÉREZ-BUSTOS; MÁRQUEZ, 2016; CORTÉSRICO; PIEDRAHITA-SOLÓRZANO, 2015).

Com efeito, nas palavras de Laura,

[...] o hardware foi literalmente bordado com linhas condutoras e o software demandou uma contínua rememoração do ofício [craft] [executado] com as nossas próprias mãos, de modo a projetar representaçóes computacionais dos pontos do calado. (RIVERA et al., 2016, p. 61).

E

Configurar o projeto para dar responsabilidade aos usuários foi importante para garantir que a tecnologia projetada tivesse um impacto real e conduzisse a novos modos de conceber tanto as práticas de bordar quanto as de projetar tecnologia. (CORTÉS-RICO; PIEDRAHITASOLÓRZANO, 2015, p. 520).

Ou seja, o procedimento adotado pretendia ir além da identificação das urgências próprias, no caso, do grupo de bordadeiras; dos requisitos que estas poderiam querer ver satisfeitos, na solução técnica que se viesse a encontrar para tais urgências; e da conformação ético-política desse artefato. Pretendiase, adicionalmente, "modificar a estrutura dos processos de engenharia" 
(PÉREZ-BUSTOS, 2017, p. k), inspirando-se, para tanto, em saberes práticos das bordadeiras (PÉREZ-BUSTOS, 2017, p. h).

Nas duas falas de Laura citadas acima, contudo, parece que o procedimento adotado contribuiu não apenas com a fertilização da prática projetiva dela por procedimentos estruturados das bordadeiras, como, em alguma medida, com valores estéticos dessas mulheres - valores que a desafiaram ou encorajaram a conceber novos modos de projetar. Com efeito, como o vimos antes, estilos de projeto diferentes - que é o que novos modos de projetar parece querer indicar aqui - distinguem-se, via de regra, não apenas pelos procedimentos que adotam, mas pelos valores estéticos que, por fim, esses mesmos procedimentos buscam promover.

Além disso, parece pouco provável que parte do acervo imagético das bordadeiras, tâo carregado com os padróes do bordado que elas produzem e com muito do acervo comum daquelas pessoas que trabalham (com) o tecido, não tenha fertilizado o de Laura, que somente foi apresentada a essa prática e introduzida aos seus rudimentos nos tempos de imersão junto a essas trabalhadoras. Nos textos de Tania e em falas de Laura, por exemplo, o imagético do bordado é utilizado com não pouca frequência (PÉREZBUSTOS, 2017).

Mas qual é o distintivo do procedimento proposto e coconstruído por Tania, que o torna potencializador de tais fertilizaçóes? A resposta aqui parece estar em parte dos métodos empregados e no modo como o processo todo foi conduzido.

Em termos metodológicos, o processo consistiu basicamente de períodos de inserção junto às bordadeiras; de um ativo encorajamento da fala dessas mulheres, do diálogo de Laura com elas e do diálogo entre engenheiros e etnógrafas; da construção de coisas; e, como parte desta última, do aprendizado, por Laura e pelas etnógrafas, dos rudimentos do calado, a partir de aulas tomadas junto a essas bordadeiras (PÉREZ-BUSTOS, 2017).

Como, porém, assegurar o contato, fundamentalmente de Laura, com os conhecimentos das bordadeiras e, a partir disso, encorajar um diálogo de saberes - isto é, uma fertilização recíproca de acervos imagéticos, valores estéticos e procedimentos estruturados entre ela e as bordadeiras? Para isso, Laura teve não apenas que viver alguns períodos de imersão junto ao grupo de trabalhadoras e aprender os rudimentos de prática laboral delas, 
como revestir-se, nesse processo, de uma postura profundamente cuidadosa (PÉREZ-BUSTOS, 2017).

É sobretudo pela imersão e pelo aprendizado do calado que Laura pode ter algum acesso aos valores estéticos, acervos imagéticos e procedimentos estruturados das bordadeiras (PÉREZ-BUSTOS; MÂRQUES, 2016, p. 162163). É, acima de tudo, pelo cuidado que esse conhecimento não é desprezado e que as condiçóes para que o encontro, diálogo e troca de saberes se dê não são solapadas (PÉREZ-BUSTOS; MÁRQUES, 2016, p. 158-160).

\section{Problematizaçóes}

Com as duas partes anteriores, buscou-se fornecer um panorama empiricamente lastreado de parte do fenômeno tecnológico, ou do modo de ser da tecnologia produzida hoje. A segunda parte do artigo sumariza uma reflexão já bem estabelecida e desenvolvida. A terceira, por outro lado, sistematiza uma dimensão que parece grandemente desconhecida ou negligenciada, seja por quem constrói a tecnologia, seja por quem reflete sobre ela. Nesta quarta parte, serão apontadas fragilidades na reflexão filosófica sobre a tecnologia ou em certos usos dessas reflexóes, em dois âmbitos específicos: no de alguns desafios nem sempre considerados para se proceder à democratização da tecnologia, como esta é pensada pelo construtivismo crítico de Andrew Feenberg (2019a, 2019b); no de um suposto purismo axiológico do desenvolvimento autêntico dos objetos técnicos, à maneira como isso é encontrado na filosofia de Gilbert Simondon.

\subsection{LIMITES DA DEMOCRATIZAÇÁO}

No que se refere à democratização do desenvolvimento tecnológico, tem-se, por um lado, a corroboração empírica da viabilidade disso, assim como metodologias amplamente testadas e bastante aprimoradas para subsidiar tal coisa (parte 2). Por outro lado, contudo, esses mesmos dados apontam gargalos ou limites de tal processo democratizante ou emancipador. São gargalos ou limites nem sempre considerados em reflexôes sobre a tecnologia ou defesas da democratização dela mais engajadas, em termos políticos.

No âmbito das atuações locais, como a do projeto com as bordadeiras colombianas, os limites ou desafios à democratização-emancipação são metodológicos. Eles se referem, de forma preponderante, à escuta e à 
incorporação efetivas e em igualdade de condiçôes dos coprojetistas - com seus valores ético-políticos, mas também com suas cosmovisóes, saberes e valores estéticos - ao projeto. Quando se trata de grupos socioeconomicamente marginais, tal desafio pode ser ainda maior. $\mathrm{O}$ trabalho com as bordadeiras colombianas (PÉREZ-BUSTOS, 2017) ilustra bem isso: mesmo bem intencionados e convictos da perspectiva empoderadora de projeto que buscam desenvolver, os projetistas, não raro, impóem seus valores e compreensóes de mundo, assumindo uma postura paternalista e construindo, em alguma medida, soluçóes técnicas para, em lugar de com, os coprojetistas.

O êxito desse projeto colombiano indica que a incorporação do cuidado, ao lado da imersão na realidade e, no caso, na atividade laboral do grupo de coprojetistas, parecem ser aspectos fundamentais para que uma abordagem projetiva emancipadora possa ser potencializada. Algo em linha semelhante parece ser confirmado por abordagens em engenharia popular (NEPOMUCENO et al., 2019; Techné) e no projeto de arquitetura (GUIZZO, 2019; Techné). Neste segundo caso, a metodologia adotada, ao se calcar na estimulação sensorial dos coprojetistas e na busca por se acessar o inconsciente deles, aponta uma segunda dimensão usualmente negligenciada em projetos técnicos (mesmo emancipadores) e na reflexão sobre eles, para além da perspectiva do cuidado e da imersão na realidade do grupo apoiado, que é a da corporeidade e do inconsciente dos coprojetistas, a qual pode ter impacto significativo no projeto técnico e na emancipação do grupo.

Outro desafio concernente à democratizaçáo do desenvolvimento tecnológico é o da sua escalabilidade. Se é inegável que existem metodologias que, aplicadas segundo o imperativo adicional do cuidado, podem produzir ao menos parte da emancipação buscada, também é verdade que elas tendem a ser mais exitosas, quanto mais local for a solução almejada, isto é, quanto menos plural for o âmbito de seus usos possíveis e menos numeroso e diverso for o grupo de coprojetistas.

Para se haver com esse segundo limitante, práticas de technology assessment poderiam ser interessantes, em suas três vertentes: assessoramento de políticas públicas, promoção de debate público e conformação da tecnologia (GRUNWALD, 2015). Tais práticas, adotadas no domínio macro das demandas de uma sociedade (ou um conjunto plural e diverso de grupos e atores sociais), poderiam ser, nesses termos, complementares à atuaçáo micro dos projetos emancipadores. 
Não obstante, de uma parte, permaneceriam questóes metodológicas atinentes, por exemplo, a como se promover o debate, o cuidado e um autêntico diálogo de saberes e, por meio disso, alcançar-se algo próximo a um consenso entre atores táo numerosos e com valores, cosmovisóes e interesses distintos e, frequentemente, conflitantes. De outra parte, e porque se abandona o lugar marginal de experiências pontuais e que pouco afetam o status quo tecnocrático e capitalista, iniciativas mais amplas ou menos locais tenderão a encontrar resistência ou oposiçáo crescentes da parte de atores sociais altamente poderosos. Além disso, e de forma mais radical, pode-se mesmo questionar o imperativo da escalabilidade: em outros mundos possíveis, que não sejam regidos pelas urgências do consumo, do controle e do lucro, toda solução sociotécnica - ou mesmo a maior parte delas - precisa de fato ser escalável, ou seja, replicável? A reaplicação da tecnologia social (DAGNINO et al., 2004) não poderia ser uma alternativa mais interessante?

Por fim, e naquilo que mais diretamente concerne à principal reflexão desenvolvida neste artigo, um quarto desafio à democratização relaciona-se à viabilidade de se produzirem as soluçóes mais adequadas para os desafios sociotécnicos em questão. Aqui, como se buscou evidenciar ao longo da terceira parte deste trabalho, se não cuidarmos da pluralização de procedimentos estruturados, valores estéticos e acervos imagéticos, poderemos seguir marcando passo em desenvolvimento, que, não obstante, pode ser alcançável, desde que se assegurem as condiçóes de possibilidade para tanto, ou seja, essa pluralizaçáo.

\subsection{O LASTRO SOCIOCULTURAL DA INVENÇÁo}

Quanto à matização de Simondon (1989 [1958], 2008 [1965-1966], 2009 [1968]), ela parece ser necessária para atualizar a compreensão do autor, incorporando a esta entendimentos sobre a tecnologia que foram se impondo apenas a partir da última década de sua vida.

Como analisado em outra parte (CRUZ, 2017, p. 72-82), a perspectiva simondoniana do desenvolvimento autêntico do indivíduo técnico, embora pretenda subordinar tal processo aos mecanismos de individuação do objeto técnico, na relação que aquele inevitavelmente estabelece com o meio que lhe é associado, dissociando tal coisa de pressóes sociais ilegítimas, resguarda inadvertidamente um espaço para que o viés social se imiscua mesmo no desenvolvimento autêntico. 
Isso se materializa na condição psicológica, a qual, para Simondon, preside à invençáa (de um novo objeto técnico ou de uma variedade melhor de algum já existente): uma tensão que o inventor experimenta entre aquilo que o autor chama de ordem da realidade - isto é, o tecnicamente dado e já passível de ser obtido na cultura técnica a que o inventor pertence - e a ordem do resultado - aquilo que ainda não é tecnicamente possível, mas que se apresenta ao inventor como desejável de sê-lo (SIMONDON, 2008, p. 139-44).

Está nisso do "mostrar-se desejável” ao inventor a porta deixada aberta, por Simondon, para que interesses ou lastros sociais assumam papel não desprezível no desenvolvimento tecnológico (autêntico). E isso não é propriamente um paradoxo com respeito à compreensão geral do autor, segundo a qual, ainda que tenha sua própria normatividade e que seja digna em si mesma, a técnica opera fundamentalmente como mediadora e harmonizadora entre o ser humano e o mundo natural, mundo que habitamos com ela (SIMONDON, 1989, p. 88, 126-128, 164; 2009, p. 107, 110, 116, 127; 2008, p. 186).

Ora, se aquilo que damos conta de inventar, precisamos ser capazes, antes, de vislumbrar, e de vislumbrar como desejável, então, inventores pertencentes a grupos sociais distintos, com suas urgências, com seus ideais e valores ético-sociais, com seus acervos imagéticos, valores estéticos e procedimentos estruturados próprios, tenderão a enxergar - e a identificar como desejáveis - soluçôes diferentes. Adicionalmente, e em sentido negativo, inventores com cidadanias ético-social e estético-cultural diferentes poderiam ser incapazes tanto de identificar urgências de grupo que não o seu quanto de conceber soluçóes para elas que fossem legítimas (ou o mais legítimo possível) para o referido grupo.

De uma parte, nisso que Simondon identifica como a condição psicológica para a invenção, certo conjunto ou léxico de imagens, certos valores estéticos e/ou certos procedimentos estruturados podem ser fundamentais para possibilitar enxergar materializaçóes possíveis do que se mostra como tecnicamente desejado, e que, em algum momento, se torna também tecnologicamente alcançável. ${ }^{8}$ No caso da nanotecnologia, analisado anteriormente, por exemplo, não fossem a representação imagética

\footnotetext{
${ }^{8}$ Feenberg (2019b, cap. 3) aproxima-se dessa mesma compreensão, ao tomar o exemplo da invenção do FAX e da calculadora, pelos japoneses, vinculando-os ao valor ou ideal de miniaturizaçáo presente na cultura nipônica. Contudo, ele não avança ou sistematiza essa reflexão, parecendo não ter notado ou dado importância a tal achado.
} 
das estruturas moleculares, o fascínio pela construção de moléculas com representaçóes similares a objetos macroscópicos e procedimentos que foram sendo desenvolvidos para realizar a esta, todo esse campo técnico não teria sido viabilizado.

De outra parte, os avanços ou invençóes requerem, para serem percebidos como possíveis, ou reconhecidos como dignos de atenção e de trabalho, para serem materializados, o fato de serem desejados ou de se mostrarem desejáveis. Ou seja, apenas quando o inventor já nutre o desejo, mesmo que não de todo consciente, por certa possibilidade técnica, ou quando, em face dela, reconhece seu valor (que pode ser o de obtenção de lucro com ela), é que ela poderá de fato vir à luz.

Assim, seja para a identificação de novas possibilidades técnicas em um artefato já existente, seja para a concepçáo de novos artefatos ou funcionalidades, os acervos imagéticos, valores estéticos e procedimentos estruturados a conformarem a prática projetiva do inventor ou equipe técnica desempenham papel não desprezível.

\section{ConsideraçóEs Finais}

Ao longo deste artigo, buscou-se mostrar que a tecnologia e o seu desenvolvimento são um fenômeno lastreado socialmente em ao menos uma dimensão adicional àquela já reconhecida pela literatura da área, relativa a valores ético-políticos. Com efeito, valores estéticos, acervos imagéticos e procedimentos estruturados desempenham, como se explicitou, significativo papel conformador da prática projetiva. A pluralização deles, nesse sentido, pode tornar passível de serem implementadas ou mesmo concebidas soluçóes sociotécnicas que, sem tal pluralização, seriam impossíveis.

Dar-se conta dessa dimensão tem relevância tanto teórica, no sentido de nos permitir conhecer o fenômeno (socio)técnico de forma mais precisa, quanto prática, já que a democratização da tecnologia e do seu desenvolvimento (ou mesmo o desenvolvimento de invençóes ou aprimoramentos na tecnologia convencional/capitalista) pressupôe (ou pode pressupor) tal pluralização.

Ainda que nem sempre impacte a prática de projetistas que estão ligados às iniciativas mais radicalmente democratizantes (em parte, por seguir ainda muito fechada em si e dialogando consigo mesma), a filosofia da tecnologia pode ter um papel importante em esclarecer e subsidiar técnicos e outras 
pessoas comprometidas com a coconstrução de outras ordens sociotécnicas possíveis. Para tanto, um primeiro passo fundamental é que os filósofos se acerquem mais da tecnologia, à maneira como ela se manifesta - ou pode se manifestar - e é produzida no mundo. A virada empírica nessa área de estudo, que produziu como principais correntes o construtivismo crítico e a pósfenomenologia (FRANSSENN et al., 2016), tem precisamente essa intenção. Contudo, passos adicionais ainda precisam ser dados.

Há algo em comum entre as três abordagens ao projeto técnico mencionadas no início da parte 4 (a colombiana, a engenharia popular e a da arquitetura), que pode ser uma pista relevante quanto a tais passos adicionais. Essas abordagens se filiam a perspectivas teórico-práticas, as quais, de um modo ou de outro, são parte ou estabelecem profícuo diálogo com a reflexão descolonial, do tipo daquela proposta por Anzaldúa (2002), Mignolo (2011) e Escobar (2018). A descolonizaçáo que essas abordagens produzem não tem apenas a ver com a superação do epistemicídio (SANTOS, 2016), abrindose para um diálogo com saberes, valores e cosmovisôes não ocidentaiscolonizadores, mas também, e como consequência dessa abertura e desse diálogo, com o resgate, no projeto técnico, de dimensôes como a do cuidado, do corpo e do inconsciente.

Talvez, nessa perspectiva descolonial, fazer filosofia da tecnologia signifique fazer uma filosofia das tecnologias possiveis, algo que parece requerer a desessencialização de aspectos contingentes do fenômeno tecnológico, mas que são (ou parecem ser) fundamentais para a tecnologia ocidental (capitalista/ convencional), e que podem ter sido tomados, inadvertidamente, como necessários até agora.

Por outro lado, se outros mundos são possíveis, isso parece requerer também outras tecnologias, outros modos de construí-las e outros saberes que suportem esse processo. É nessa direção que apontam as três práticas projetivas mencionadas. Tal coisa não significa necessariamente a negação da tecnologia, engenharia e ciência ocidentais, mas pressupóe, ao menos, o alargamento delas, por meio do diálogo com saberes, valores e cosmovisóes que foram proscritos, desmerecidos ou "assassinados" (SANTOS, 2016), sob a pretensão universalista, desterritorializada e descorporificada inclusive, e eventualmente, sobretudo, do conhecimento filosófico ocidental (DUSSEL, 2008; ESCOBAR, 2018). 
Pode-se dizer que as problematizaçôes desenvolvidas na parte 4 deste artigo são um exemplo dessa descolonização da filosofia da tecnologia, materializado no reconhecimento de uma engenharia menos científica - e mais artística -; em práticas projetivas "técnico-sociais" e que têm muito a ganhar, se são coconstruídas pelos coprojetistas e em profundo diálogo com seus saberes, valores e cosmovisôes; em soluçôes sociotécnicas reaplicáveis (mas não replicáveis), cujo processo projetivo é libertador e cujo impacto social é descolonizador, de emulaçáo de outro mundo possível, no geral mais solidário, socialmente justo e ecologicamente sustentável.

Seguir a trilha da descolonização da filosofia da tecnologia parece não apenas promissor, como necessário. Contudo, para corroborar ou refutar tal hipótese, ou para saber a dimensáo desse eventual impacto descolonizador, mais estudos precisam ser desenvolvidos.

CRUZ, C. C. Aesthetic values, image collections, and structured procedures: widening and decolonizing the philosophical reflection on technology. Trans/form/ação, Marília, v. 44, p. 207-230, 2021. Dossier Tecnica.

\begin{abstract}
Since the 1980s, technical-scientific knowledge, instrumental and cognitive values as well as ethical-political values are acknowledged as constitutive parts of technology and its development. However, a fourth category of elements that shapes design continues to be largely neglected or unknown: image collections, aesthetical values, and structured procedures. Disregarding such elements impose limits on the technical development. In this manuscript, I present this fourth category elements, its impact on the designing practice, and a way of pluralizing its contents. I also sketch two of the most successful approaches for democratizing the technical development. Then, I discuss: some limits and potentialities of democratizing technology; an actualization of part of Simondon's understanding of technical development; the theoretical and practical necessity of decolonizing (or continuing the decolonization of) the philosophy of technology.
\end{abstract}

Keywords: Aesthetic Values. Image Collections. Structured Procedures. Democratization. Decolonization. 


\section{REFERÊNCIAS}

AMMON, S. Image-Based Epistemic Strategies in Modeling: Designing Architecture After the Digital Turn. In: AMMON, S.; CAPDEVILA-WERNING, R. (ed.). The active image: architecture and engineering in the age of modeling. Suíça: Springer International, 2017. p. 177-206.

AMMON, S.; CAPDEVILA-WERNING, R. (ed.). The active image: architecture and engineering in the age of modeling. Suíça: Springer International, 2017.

ANZALDÚA, G. now let us shift... the path of conocimiento... inner work, public acts. In: ANZALDUA, G.; KEATING, A (org.). This bridge we call home. New York: Routledge, 2002. p. 540-578.

BALL, P. Elegant Solutions: Ten Beautiful Experiments in Chemistry. Cambridge: The Royal Society of Chemistry, 2005.

BANNON, L.; EHN, P. Design: Design Matters in Participatory Design. In: SIMONSEN, J. \& ROBERTSON, T. (ed.) Routledge International Handbook on Participatory Design. London \& New York: Routledge, 2013. p. 37-63.

CORTÉS-RICO, L.; PIEDRAHITA-SOLÓRZANO, G. Participatory Design in Practice: The Case of an Embroidered Technology. In: ABASCAL, J. et al. (ed.). IFIP TC 13 INTERNATIONAL CONFERENCE, 15., Bamberg, Germany: September 14-18, 2015. Proceedings [...], Part III, 2015.

CRUZ, C. Tecnologia social: fundamentaçôes, desafios, urgência e legitimidade. 2017, 280 f. Tese (Doutorado) - Faculdade de Filosofia, Letras e Ciências Humanas, Departamento de Filosofia, Universidade de São Paulo, São Paulo, 2017.

CRUZ, C. Assessing Grassroots Engineering Applications in Brazil. In: ASEE VIRTUAL ANNUAL CONFERENCE CONTENT ACCESS, Virtual Online, 2020. Disponível em: https://peer.asee.org/34176. Acesso em: 15 nov. 2020.

CURRIE, G. Aesthetics and Cognitive Science. In: LEVINSON, J. (ed.). The Oxford Handbook of Aesthetics. Oxford: Oxford University Press, 2003. p. 876-896.

DAGNINO, R.; BRANDĀO, F.; NOVAES, H. Sobre o marco analítico-conceitual da tecnologia social. In: LASSANCE JÚNIOR, A. E. et al. (ed.). Tecnologia social: uma estratégia para o desenvolvimento. Rio de Janeiro: Fundação Banco do Brasil, 2004. p. 15-64.

DUSSEL, E. A new age in the history of philosophy: the world dialogue between philosophical traditions. Prajñâ Vihâra, v. 9, n. 1, p. 1-22, 2008.

DYM, C.; LITTLE, P. Introdução à engenharia: uma abordagem baseada em projeto. Tradução de João Tortello. Porto Alegre: Bookman, 2010.

ELLUL, J. La technique ou l'enjeu du siècle [1954]. Paris: Économica, 2008.

ELLUL, J. Le systhème technicien [1977]. Paris: Cherche Midi, 2012. 
ESCOBAR, A. Designs for the Pluriverse: Radical Interdependence, Autonomy, and the Making of Worlds. Durham and London: Duke University Press, 2018.

FEENBERG, A. Questioning Technology. New York: Routledge, 1999.

FEENBERG, A. Entre a razão e a experiência: ensaios sobre tecnologia e modernidade [2010]. Tradução de E. Beira, C. Cruz e R. Neder. Vila Nova de Gaia: Inovatec, 2019a.

FEENBERG, A. Tecnossistema: a vida social da razão [2017]. Tradução de E. Beira e C. Cruz. Vila Nova de Gaia: Inovatec, 2019b.

FERGUSON, E. Engineering and the mind's eyes. Cambridge: The MIT Press, 1992.

FRAGA, L.; ALVEAR, C.; CRUZ, C. Na trilha da contra-hegemonia da engenharia no Brasil: da Engenharia e Desenvolvimento Social à Engenharia Popular. Revista Iberoamericana de Ciencia, Tecnología y Sociedad - CTS, v. 14, n. 43, 2020 (no prelo).

FRANSSEN, M.; VERMAAS, P.; KROES, P; MEIJERS, A. (ed.) Philosophy of Technology after the Empirical Turn. Dordrecht: Springer, 2016. Disponível em: https:// doi.org/10.1007/978-3-319-33717-3. Acesso em: 10 nov. 2020.

FREIRE, P. Extensão ou comunicação? [1969]. Tradução de Rosisca de Oliveira. Rio de Janeiro: Paz e Terra, 1983.

FREIRE, P.; SHOR, I. Medo e Ousadia: O Cotidiano do Professor. Tradução de Adriana Lopez. Rio de Janeiro: Paz e Terra, 1986.

FREIRE, P. Pedagogia do Oprimido. [1970] Rio de Janeiro: Paz e Terra, 1987.

GOLDSCHMIDT, G. Manual Sketching: why is it still relevant? In: AMMON, S.; CAPDEVILA-WERNING, R. (ed.). The active image: architecture and engineering in the age of modeling. Suíça: Springer International, 2017. p. 77-97.

GUIZZO, I. Reativar territórios: o corpo e o afeto na questão do projeto participativo. Belo Horizonte: Quintal, 2019.

HEIDEGGER, M. The question concerning technology [1955]. Trans. William Lovitt. NY \& London: Garland, 1977.

HEIDEGGER, M. Traditional Language and Technological Language [1962]. Trans. Wanda T. Gregory. Journal of Philosophical Research, v. 23, p. 130-145, 1998.

HORKHEIMER, M.; ADORNO, T. Dialectic of enlightenment. Tradução de Edmund Jephcott. Stanford: Stanford University Press, 2002 [1944].

IVERSEN, O.; HALSKOVA, K.; LEONG, T. Values-led participatory design. CoDesign, v. 8, n. 2-3, p. 87-103, 2012.

KROES, P.; VAN DE POEL, I. Design for Values and the Definition, Specification, and Operationalization of Values. In: VAN DEN HOVEN, J.; VERMAAS, P.; VAN DE POEL, I (ed.). Handbook of Ethics, Values, and Technological Design. Dordrecht: Springer, 2015. p. 151-178. 
LATOUR, B. Where are the missing masses? The sociology of a few mundane artifacts. In: BIJKER, W.; LAW, J. (ed.). Shaping Technology/Building Society: Studies in Sociotechnical Change. Cambridge, Mass.: MIT Press, 1992. p. 225-258.

MARCUSE, H. One-Dimensional Man [1964]. London \& New York: Routledge, 2002.

MIGNOLO, W. Epistemic Disobedience and the Decolonial Option: A Manifesto. Transmodernity: Journal of Peripheral Cultural Production of the Luso-Hispanic World, v. 1, n. 2, p. 44-66, 2011.

NEPOMUCENO, V. et al. Uma proposta metodológica para assessoria técnica às empresas recuperadas por trabalhadores a partir da engenharia popular: combinando pesquisa-ação, adequação sociotécnica e análise ergonômica do trabalho. In: ARAÚJO, F. et al. Dialética da autogestão em empresas recuperadas por trabalhadores no Brasil. Marília: Lutas Anticapital, 2019. p. 47-91.

PAHL, G.; BEITZ, W., FELDHUSEN, J.; GROTE, K. Projeto na engenharia. Tradução de Hans Werner. São Paulo: Blucher, 2005.

PÉREZ-BUSTOS, T. Thinking with Care. Unraveling and mending in an ethnography of craft embroidery and technology. Revue d'anthropologie des connaissances, v. 11, n. 1, p. a-u, 2017.

PÉREZ-BUSTOS, T.; MÁRQUEZ, S. Destejiendo puntos de vista feministas: reflexiones metodológicas desde la etnografía del diseño de una tecnología. Revista Iberoamericana CTS, v. 31, n. 11, p. 147-69, 2016.

PINCH, T; BIJKER, W. The social construction of facts and artifacts: or how sociology of science and the sociology of technology might benefit each other. In: BIJKER, W.; HUGHES, T.; PINCH, T. The social construction of technological systems: New directions in the sociology and history of technology. Cambridge, Mass.: MIT Press, 1989.

RIEDER, B.; SCHÄFER, M. Beyond Engineering: Software Design as Bridge over the Culture/Technology Dichotomy. In: VERMAAS, P.; KROES, P.; LIGHT, A.; MOORE, S. (ed.). Philosophy and Design: From Engineering to Architecture. Dordrecht: Springer Netherlands, 2008. p. 159-71.

RIVERA, R.; CORTÉS-RICO, L.; PÉREZ-BUSTOS, T.; FRANCO-AVELLANEDA, $M$. Embroidering engineering: a case of embodied learning and design of a tangible user interface. Engineering Studies, v. 8, n. 1, p. 48-65, 2016.

ROBERTSON, T.; SIMONSEN, J. Participatory Design - An introduction. In: SIMONSEN, J.; ROBERTSON, T. (ed.) Routledge International Handbook on Participatory Design. London \& New York: Routledge, 2013. p. 1-17.

SANTOS, B. Epistemologies of the South: justice against epistemicide. New York: Routledge, 2016. 
SCHUMMER, J.; MACLENNAN, B.; TAYLOR, N. Aesthetic Values in Technology and Engineering Design. In: MEIJERS, A. (ed.). Philosophy of technology and engineering science. Amsterdam: Elsevier B. V., 2009. p. 1031-1068.

SIMONDON, G. Du mode d'existence des objets techinques. Paris: Aubier, 1989 [1958].

SIMONDON, G. Imagination et Invention. Chatou: Les Éditions de La Transparence, 2008 [1965-1966].

SIMONDON, G. Entretien sur la mécanologie. Revue de synthèse: tomo 130, 6a série, n. 1, p. 103-132, 2009 [1968].

SPITAS, C. Analysis of systematic engineering design paradigms in industrial practice: a survey. Journal of Engineering Design, v. 22, n. 6, p. 427-445, 2011 a.

SPITAS, C. Analysis of systematic engineering design paradigms in industrial practice: scaled experiments. Journal of Engineering Design, v. 22, n. 7, p. 447-465, 2011 b.

SUWA, T.; GERO, J.; PURCELL, T. Unexpected discoveries and S-invention of design requirements: important vehicles for a design process. Design Studies, v. 21, n. 6, p. 539$567,2000$.

THOMAS, H. De las tecnologías apropiadas a las tecnologías sociales. Conceptos/ estrategias/diseńos/acciones. In: PRIMERAS JORNADAS DE TECNOLOGÍAS SOCIALES. Programa Consejo de la Demanda de Actores Sociales - MINCyT. Buenos Aires, 14 maio 2009.

VAN DE POEL, I. Values in Engineering Design. In: MEIJERS, A. (ed.). Philosophy of technology and engineering science. Amsterdam: Elsevier B. V., 2009. p. 973-1006.

VAN DE POEL, I. Design for Values in Engineering. In: VAN DEN HOVEN, J.; VERMAAS, P.; VAN DE POEL, I. (ed.). Handbook of Ethics, Values, and Technological Design. Dordrecht: Springer, 2015. p. 667-90.

VAN DER VELDEN, M.; MÖRTBERG, C. Participatory Design and Design for Values. In: VAN DEN HOVEN, J.; VERMAAS, P.; VAN DE POEL, I. (ed.). Handbook of Ethics, Values, and Technological Design. Dordrecht: Springer, 2015. p. 41-66.

VINCENTI, W. What engineers know and how they know it. London: The John Hopkins University Press, 1990.

WINNER, L. Artefatos têm política? Analytica, Rio de Janeiro, v. 21, n. 2, p. 195-218, 2017 [1986].

Recebido: 08/01/2021

Aceito: 08/3/2021 